\title{
The Association Between the Tumor Necrosis Factor-Alpha Gene-308A/G Polymorphism and Chronic Pancreatitis: A Meta-Analysis
}

\author{
Xiao-qin Zhang, ${ }^{*}$ Ling-ai Pan, ${ }^{*}$ Hong-li He, Rong-an Liu, Xiao-xiao Wu, and Xiao-bo Huang
}

Background: Tumor necrosis factor-alpha (TNF- $\alpha$ ) is a major proinflammatory cytokine that has been posited to be involved in the development of chronic pancreatitis (CP). Several studies have been carried out that explored the association between the TNF- $\alpha-308 \mathrm{~A} / \mathrm{G}$ polymorphism and CP; however, conflicting results have emerged. The aim of this study was to perform a meta-analysis to provide a more precise assessment of the relationship between the TNF- $\alpha-308 \mathrm{~A} / \mathrm{G}$ polymorphism and CP risk.

Methods: Case-control studies were identified using PubMed, Embase, Web of Science, Cochrane Library, and Chinese National Knowledge Infrastructure through January 2019 from which seven were identified that met all inclusion criteria.

Results: This meta-analysis included $695 \mathrm{CP}$ cases and 742 controls. A positive association was found between the A allele and the risk of $\mathrm{CP}$ using the additive model (OR [odds ratio] $=1.83,95 \% \mathrm{CI}$ [confidence interval $=1.08-3.10)$. We also found, after excluding the Hardy-Weinberg equilibrium-violating studies, that the AA genotype was significantly associated with $\mathrm{CP}$ in both the additive and recessive models $(\mathrm{OR}=2.28,95 \%$ $\mathrm{CI}=1.27-4.07 ; \mathrm{OR}=2.19,95 \% \mathrm{CI}=1.26-3.81$ ).

Conclusion: This meta-analysis indicates that the A allele of the TNF- $\alpha-308 \mathrm{~A} / \mathrm{G}$ polymorphism increases the risk of $\mathrm{CP}$.

Keywords: meta-analysis, tumor necrosis factor-alpha, polymorphism, chronic pancreatitis

\section{Introduction}

C HRONIC PANCREATITIS (CP) is one of the most difficult diseases to treat due to the retroperitoneal location of the pancreas and the autodestruction caused by the disease. Chemokines have been regarded as important factors in the development of CP (Saurer et al., 2000; Inoue et al., 2002; Ito, 2007). Previous studies have suggested that chemokines could influence inflammation by increasing fibrosis, which is one of the important features of CP. Tumor necrosis factor alpha $(\mathrm{TNF}-\alpha)$ has been studied as a proinflammatory cytokine with strong immunostimulatory activity (Vassalli, 1992). It participates in the inflammatory responses through stimulating the production of other cytokines, increasing the expression of adhesion molecules, and activation of neutrophils (Vassalli, 1992). TNF- $\alpha$ has also been regarded as a costimulator of $\mathrm{T}$ cell activation, and antibody production by $\mathrm{B}$ cells. The production of TNF- $\alpha$ varies from individual to individual, and depends, in part, on the polymorphisms of this gene. The G-to-A transition at position -308 in the promoter region is associated with an elevated expression of TNF- $\alpha$. Yet, previous meta-analyses did not find a significant association between the $-308 \mathrm{~A} / \mathrm{G}$ polymorphism and acute pancreatitis risk (Yang et al., 2012; Yin et al., 2012). However, there is still controversy and uncertainty about the association between the TNF- $\alpha-308 \mathrm{~A} / \mathrm{G}$ polymorphism and the risk of CP. This is potentially due to study design and the limited number of cases and participants in each individual study. Thus, this meta-analysis was performed to explore the association between the TNF- $\alpha$ gene $-308 \mathrm{~A} / \mathrm{G}$ polymorphism and $\mathrm{CP}$ risk.

\section{Methods}

Search strategy, inclusion criteria, and data extraction

Relevant articles reporting on the association of the TNF- $\alpha$ $-308 \mathrm{~A} / \mathrm{G}$ polymorphism and $\mathrm{CP}$ from the databases of PubMed, Embase, Web of Science, Cochrane Library, and Chinese National Knowledge Infrastructure (up to January 2019) were systematically searched. The keywords were

Department of ICU, Affiliated Hospital of University of Electronic Science and Technology \& Sichuan Provincial People's Hospital, Chengdu, China.

*X.-q.Z. and L.-a.P. contributed equally as first authors. 


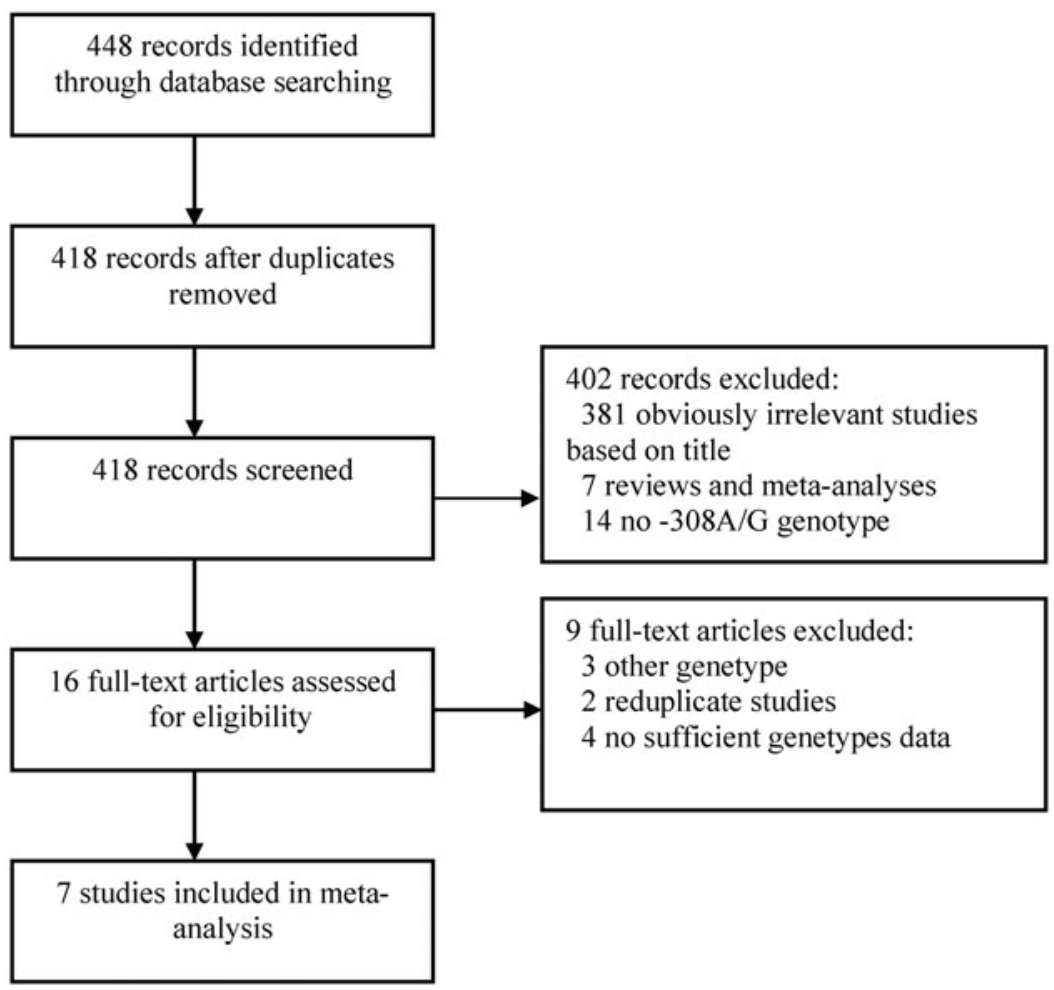

(tumor necrosis factor or TNF) and (chronic pancreatitis or $\mathrm{CP}$ ) and (polymorphism or mutation or variant). Other additional studies that could have met our inclusion criteria were manually searched. Inclusion criteria included (1) relevant articles that assessed the relationship between the TNF$\alpha-308 \mathrm{~A} / \mathrm{G}$ polymorphism alleles and CP, (2) having enough genotypes data for odds ratio (OR) calculation. The following exclusion criteria were as follows: (1) no available data from studies, (2) case reports, (3) editorial articles, and (4) reviews and meeting summaries. For each study, the relevant data were extracted: the first author's name, publication year, source of controls, country, ethnicity, sample size, and available genotype data for TNF- $\alpha-308 \mathrm{~A} / \mathrm{G}$.

\section{Statistical analyses}

An association analysis was performed using four genetic models, dominant (AA + GA vs. GG), recessive (AA vs. GA + GG), additive (AA vs. GG), and allelic (A allele vs. G allele) to calculate the overall OR and 95\% CI (confidence interval) using the original data provided in each article concerning the relationship between the TNF- $\alpha-308 \mathrm{~A} / \mathrm{G}$ polymorphism and CP. The $I^{2}$ statistic was used to estimate the degree of heterogeneity among the studies. If the $I^{2} \geq 50 \%$, the random-effect model was used, otherwise, the fixed-effect model was used. HardyWeinberg equilibrium (HWE) in the controls was evaluated by the $\chi^{2}$ test (Hoaglin, 2014). Subgroup analyses based on

Table 1. Characteristics of Studies Included in the Meta-Analysis

\begin{tabular}{|c|c|c|c|c|c|c|c|c|c|c|c|c|c|}
\hline \multirow[b]{2}{*}{ References } & \multirow{2}{*}{$\begin{array}{l}\text { Control } \\
\text { source }\end{array}$} & \multirow[b]{2}{*}{ Country } & \multirow[b]{2}{*}{ Ethnicity } & \multirow{2}{*}{$\begin{array}{l}\text { Number } \\
\text { of cases }\end{array}$} & \multirow{2}{*}{$\begin{array}{l}\text { Number } \\
\text { of controls }\end{array}$} & \multicolumn{3}{|c|}{ Cases } & \multicolumn{3}{|c|}{ Controls } & \multicolumn{2}{|c|}{$H W E$} \\
\hline & & & & & & $G G$ & $G A$ & $A A$ & $G G$ & $G A$ & $A A$ & $\chi^{2}$ & $\mathrm{p}$ \\
\hline $\begin{array}{l}\text { Beranek et al. } \\
\text { (2003) }\end{array}$ & $\begin{array}{l}\text { Population- } \\
\text { based }\end{array}$ & Germany & Caucasian & 284 & 116 & 203 & 77 & 4 & 81 & 34 & 1 & 1.61 & 0.204 \\
\hline $\begin{array}{l}\text { Schneider et al. } \\
\text { (2003) }\end{array}$ & $\begin{array}{l}\text { Population- } \\
\text { based }\end{array}$ & $\begin{array}{l}\text { United } \\
\text { States }\end{array}$ & Caucasian & 93 & 94 & 68 & 24 & 1 & 64 & 27 & 3 & 0.01 & 0.941 \\
\hline Howell et al. (2005) & $\begin{array}{l}\text { Population- } \\
\text { based }\end{array}$ & $\begin{array}{l}\text { United } \\
\text { Kingdom }\end{array}$ & Caucasian & 50 & 214 & 38 & 11 & 1 & 146 & 56 & 12 & 4.14 & 0.042 \\
\hline Farkas et al. (2007) & $\begin{array}{l}\text { Population- } \\
\text { based }\end{array}$ & Hungary & Caucasian & 83 & 75 & 56 & 21 & 6 & 52 & 21 & 2 & 0.00 & 0.945 \\
\hline $\begin{array}{l}\text { Talar-Wojnarowska } \\
\text { et al. (2009) }\end{array}$ & $\begin{array}{l}\text { Population- } \\
\text { based }\end{array}$ & Poland & Caucasian & 56 & 50 & 32 & 21 & 3 & 31 & 17 & 2 & 0.03 & 0.861 \\
\hline $\begin{array}{l}\text { Sri Manjari et al. } \\
\text { (2014) }\end{array}$ & $\begin{array}{l}\text { Population- } \\
\text { based }\end{array}$ & India & Indian & 100 & 100 & 35 & 33 & 32 & 50 & 36 & 14 & 2.99 & 0.084 \\
\hline $\begin{array}{l}\text { Bendicho et al. } \\
\text { (2005) }\end{array}$ & $\begin{array}{l}\text { Population- } \\
\text { based }\end{array}$ & Brazil & $\begin{array}{r}\text { Mixed } \\
\text { race }\end{array}$ & 29 & 93 & 23 & 6 & 6 & 73 & & 20 & - & - \\
\hline
\end{tabular}

HWE, Hardy-Weinberg equilibrium. 
Table 2. Association of the Tumor Necrosis Factor-Alpha -308A/G Polymorphism and Chronic Pancreatitis Risk

\begin{tabular}{|c|c|c|c|c|c|c|}
\hline Analysis model & & $\mathrm{n}$ & $\operatorname{ORr}(95 \% \mathrm{CI})$ & ORf $(95 \% C I)$ & $\mathrm{p}_{h}$ & $\mathrm{I}^{2}(\%)$ \\
\hline \multirow[t]{3}{*}{ Allelic (A vs. G) } & Total analysis & 6 & $1.09(0.77-1.54)$ & $1.14(0.93-1.40)$ & 0.022 & 61.9 \\
\hline & Caucasian & 5 & $0.94(0.73-1.20)$ & $0.93(0.73-1.19)$ & 0.513 & 0.0 \\
\hline & In HWE & 5 & $1.19(0.83-1.69)$ & $1.23(0.99-1.54)$ & 0.047 & 58.5 \\
\hline \multirow[t]{3}{*}{ Additive (AA vs. GG) } & Total analysis & 6 & $1.55(0.68-3.54)$ & $1.83(1.08-3.10)$ & 0.183 & 33.7 \\
\hline & Caucasian & 5 & $1.08(0.45-2.60)$ & $0.99(0.46-2.16)$ & 0.410 & 0.0 \\
\hline & In HWE & 5 & $2.32(1.24-4.34)$ & $2.28(1.27-4.07)$ & 0.390 & 3.0 \\
\hline \multirow[t]{3}{*}{ Recessive (AA vs. GG + GA) } & Total analysis & 6 & $1.60(0.76-3.38)$ & $1.82(1.10-3.02)$ & 0.243 & 25.5 \\
\hline & Caucasian & 5 & $1.10(0.46-2.63)$ & $1.02(0.47-2.21)$ & 0.434 & 0.0 \\
\hline & In HWE & 5 & $2.26(1.28-3.99)$ & $2.19(1.26-3.81)$ & 0.453 & 0.0 \\
\hline \multirow[t]{3}{*}{ Dominant (AA + GA vs. GG) } & Total analysis & 7 & $1.04(0.80-1.34)$ & $1.04(0.82-1.32)$ & 0.357 & 9.4 \\
\hline & Caucasian & 5 & $0.91(0.69-1.20)$ & $0.91(0.69-1.20)$ & 0.789 & 0.0 \\
\hline & In HWE & 5 & $1.12(0.82-1.51)$ & $1.11(0.85-1.45)$ & 0.291 & 19.4 \\
\hline
\end{tabular}

ORf, odd ratio for fixed-effects model; ORr, odd ratio for random-effects model; $p_{\mathrm{h}}, p$ value for heterogeneity test.

ethnicity and HWE status were also performed. In addition, we compared the results from the fixed-effect model with those from the random-effect model for the sensitivity analysis. Possible publication bias was evaluated by the Begg's funnel plot and Egger's test. All tests were two-tailed, and a $p$ value $<0.05$ was considered statistically significant. Stata 12.0 software (StataCorp LP, College Station, TX) was used for all analyses.

\section{Results}

The studies' characteristics

There were 848 records, which met our search strategy using the aforementioned databases. There were seven studies
(Beranek et al., 2003; Schneider et al., 2003; Bendicho et al., 2005; Howell et al., 2005; Farkas et al., 2007; TalarWojnarowska et al., 2009; Sri Manjari et al., 2014) that met our inclusion criteria concerning the association between the TNF- $\alpha$ gene $-308 \mathrm{~A} / \mathrm{G}$ polymorphism and $\mathrm{CP}$, involving $695 \mathrm{CP}$ cases and 742 controls. Figure 1 shows the detailed inclusion and exclusion reasoning. The countries where these studies were carried out include Germany, United States, United Kingdom, Hungary, Poland, India, and Brazil. Five of the included studies were performed using Caucasians: $566 \mathrm{CP}$ cases and 549 controls. All of the included studies were population-based case-control studies. Table 1 gives the characteristics of the included studies.

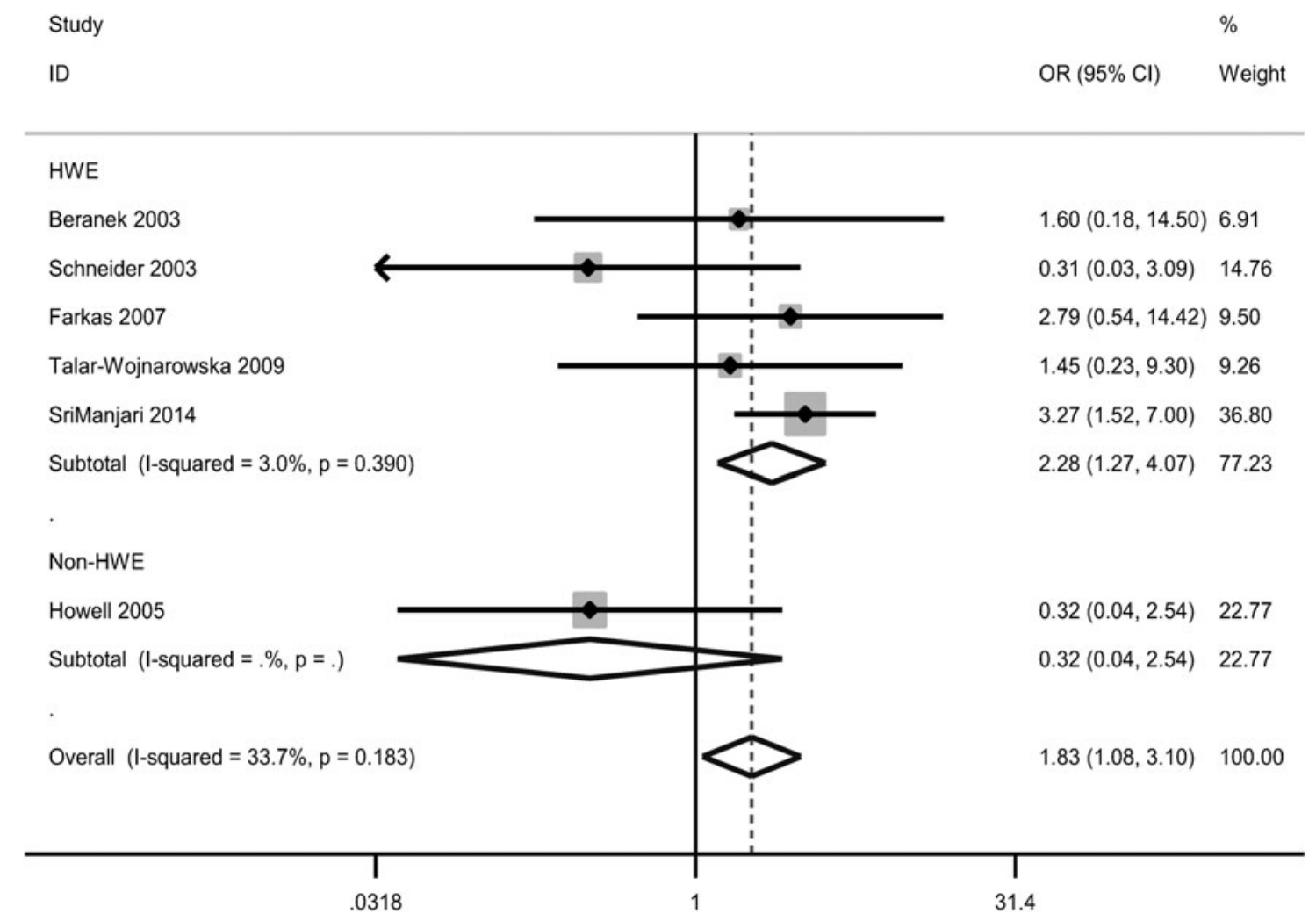

FIG. 2. The forest plot on the association between TNF- $\alpha-308 \mathrm{~A} / \mathrm{G}$ polymorphism and chronic pancreatitis risk under additive model with fixed effect analyses. TNF- $\alpha$, tumor necrosis factor-alpha. 
FIG. 3. The Begg's funnel plot for publication bias assessment under additive model.
Funnel plot with pseudo $95 \%$ confidence limits

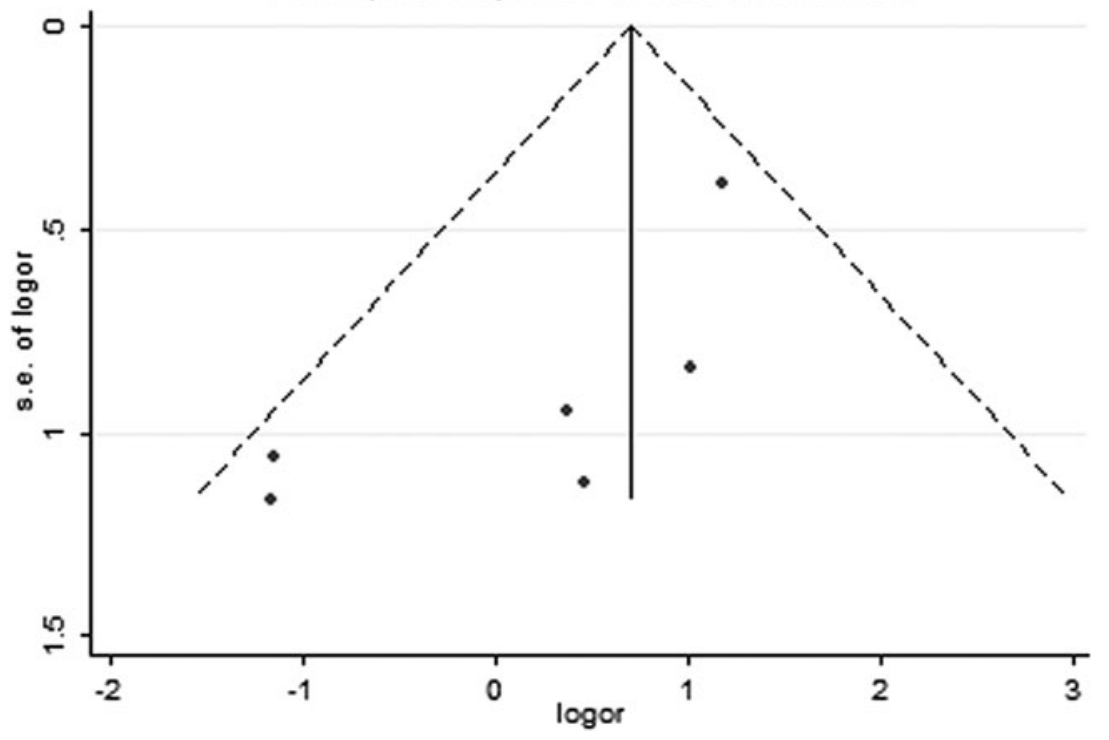

\section{Meta-analysis results}

Table 2 summarizes the assessment regarding the relationship between the TNF- $\alpha$ gene $-308 \mathrm{~A} / \mathrm{G}$ polymorphism and $\mathrm{CP}$ risk. A pooled analysis suggests that an increased risk of $\mathrm{CP}$ was found in the additive model $(\mathrm{OR}=1.83,95 \% \mathrm{CI}=1.08-$ 3.10 ), yet not in any of the other models (Table 2, Fig. 2).

A subgroup analysis by ethnicity was conducted to explore potential ethnic differences. There was no evidence for a positive relationship between the TNF- $\alpha$ gene $-308 \mathrm{~A} / \mathrm{G}$ polymorphism and $\mathrm{CP}$ risk among Caucasians for any of the genetic models (Table 2). In addition, we conducted an analysis in which we excluded the research populations that violated the HWE in control groups. The pooled results indicate that the AA genotype was significantly associated with $\mathrm{CP}$ in the additive and recessive models $(\mathrm{OR}=2.28,95 \%$ $\mathrm{CI}=1.27-4.07 ; \mathrm{OR}=2.19,95 \% \mathrm{CI}=1.26-3.81$, Table 2, Fig. 2). There was no publication bias for the meta-analyses $(t=-2.70, p=0.054$; Figs. 3 and 4$)$. The sensitivity analysis was performed, in which we found inconsistent results between the fixed-effect model and the random-effect model. Therefore, the results in our study were unstable (Table 2).

\section{Discussion}

Pancreatitis, both acute and chronic, is a complicated disease to understand and treat. It has been reported that TNF- $\alpha$ and other proinflammatory cytokines can activate pancreatic stellate cells, which play a key role in the pathogenesis of pancreatitis (Mews et al., 2002; Schneider et al., 2003). The two previously described polymorphisms were identified in the TNF- $\alpha$ promoter region: a $\mathrm{G}>\mathrm{A}$ substitution at position308 (termed TNF2 allele, wild-type TNF1 allele) and a G > A substitution at position 238 (termed TNFA allele, wild-type TNFG allele) relative to the transcription start site. The $-308 \mathrm{~A} / \mathrm{G}$ polymorphism has been implicated as being functional and mostly studied. A large number of articles have been published that have attempted to assess the relationship
FIG. 4. The Egger's linear regression for publication bias assessment under additive model.

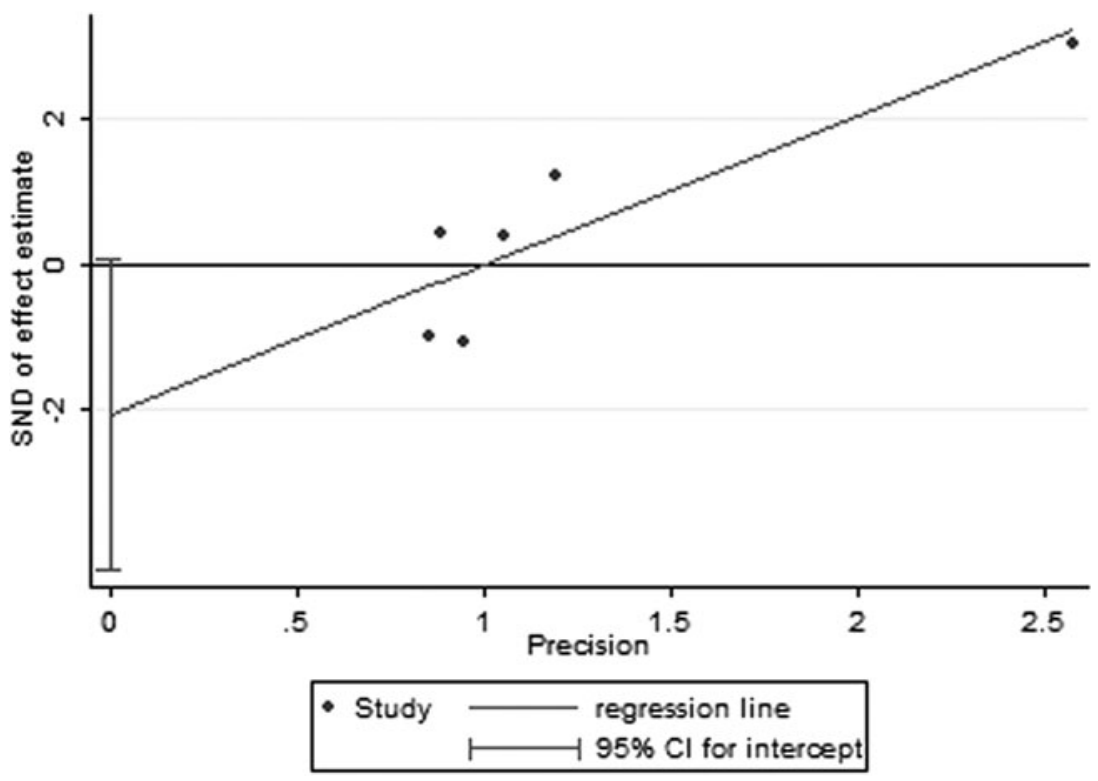


between this polymorphism and $\mathrm{CP}$ risk, with inconsistent results. Thus, a meta-analysis was performed to reanalyze the association between the $-308 \mathrm{~A} / \mathrm{G}$ polymorphism and CP risk.

Our analysis included seven studies, involving $695 \mathrm{CP}$ cases and 742 controls. These numbers provided the bases for a more thorough examination with respect to the association between the $-308 \mathrm{~A} / \mathrm{G}$ polymorphism and CP. Results from our meta-analysis suggest an increased risk for the development of $\mathrm{CP}$ with the A allele of $-308 \mathrm{~A} / \mathrm{G}$ polymorphism. A subgroup analysis was conducted to explore whether there are ethnic differences with regard to the relationship between $\mathrm{CP}$ risk and the -308 genotypes. We did not combine the results for the two Asian studies due to the fact that they were related and may have contained overlapping patient population. The results among the Caucasian studies indicate a nonsignificant association between the $-308 \mathrm{~A} / \mathrm{G}$ polymorphism and CP risk for all genetic models. However, when we performed the subgroup analysis using only those studies that had control groups that were consistent with the HWE, a significant association was found between the TNF- $\alpha$ $-308 \mathrm{~A} / \mathrm{G}$ polymorphism and $\mathrm{CP}$ risk for both the additive and recessive models. Moreover, the studies by Schneider et al. (2003) and Howell et al. (2005) seem to report an inverse association with pancreatitis. This is unexpected, because most studies (Beranek et al., 2003; Farkas et al., 2007; TalarWojnarowska et al., 2009; Sri Manjari et al., 2014) have reported increased expression of TNF- $\alpha-308 \mathrm{~A} / \mathrm{G}$ in $\mathrm{CP}$. Because of the small number of subjects studied and whether consistent with the HWE in control groups, these results must be treated with caution, but TNF- $\alpha-308 \mathrm{~A} / \mathrm{G}$ polymorphisms merit further study in a larger patient series.

From the results of sensitivity analysis, we can find that this meta-analysis is not without its limitation. First, we only searched for and included studies that were published, which meant we might have missed some nonpublished records or meeting articles that met our inclusion criteria. Second, the sample sizes and the number of the studies included in our meta-analysis were relatively small, which increased the probability of false positives or false negatives. Third, this analysis would not find other interacting genes that might play a role in CP risk. Finally, due to insufficient information, we could not conduct subgroup analyses stratified by other factors, such as gender, smoking status, and so on.

In conclusion, findings from this meta-analysis suggest that the A allele of the TNF- $\alpha-308 \mathrm{~A} / \mathrm{G}$ polymorphism is associated with the development of $\mathrm{CP}$. However, this result should be further confirmed with additional studies across additional ethnicities, because most of the available studies were conducted using Caucasian populations in this meta-analysis.

\section{Authors' Contributions}

X.-b.H. and X.-q.Z. designed the article. H.-1.H., R.-a.L., and X.-X.W. collected and analyzed the data. X.-q.Z. and L.a.P. drafted the article and all the authors approved submission.

\section{Author Disclosure Statement}

No competing financial interests exist.

\section{Funding Information}

No funding was received for this article.

\section{References}

Bendicho MT, Guedes JC, Silva NN, et al. (2005) Polymorphism of cytokine genes (TGF-beta1, IFN-gamma, IL-6, IL-10, and TNF-alpha) in patients with chronic pancreatitis. Pancreas 30:333-336.

Beranek H, Teich N, Witt H, et al. (2003) Analysis of tumour necrosis factor alpha and interleukin 10 promotor variants in patients with chronic pancreatitis. Eur J Gastroenterol Hepatol 15:1223-1227.

Farkas G Jr., Hofner P, Balog A, et al. (2007) Relevance of transforming growth factor-beta1, interleukin-8, and tumor necrosis factor-alpha polymorphisms in patients with chronic pancreatitis. Eur Cytokine Netw 18:31-37.

Hoaglin DC (2014) Assessment of heterogeneity in metaanalyses. JAMA 312:2286-2287.

Howell WM, Pead PJ, Shek FW, et al. (2005) Influence of cytokine and ICAM-1 gene polymorphisms on susceptibility to chronic pancreatitis. J Clin Pathol 58:595-599.

Inoue M, Ino Y, Gibo J, et al. (2002) The role of monocyte chemoattractant protein-1 in experimental chronic pancreatitis model induced by dibutyltin dichloride in rats. Pancreas 25:e64-e70.

Ito T (2007) Can measurement of chemokines become useful biological and functional markers of early-stage chronic pancreatitis? J Gastroenterol 42 Suppl 17:72-77.

Mews P, Phillips P, Fahmy R, et al. (2002) Pancreatic stellate cells respond to inflammatory cytokines: potential role in chronic pancreatitis. Gut 50:535-541.

Saurer L, Reber P, Schaffner T, et al. (2000) Differential expression of chemokines in normal pancreas and in chronic pancreatitis. Gastroenterology 118:356-367.

Schneider A, Pogue-Geile K, Barmada MM, et al. (2003) Hereditary, familial, and idiopathic chronic pancreatitis are not associated with polymorphisms in the tumor necrosis factor alpha (TNF-alpha) promoter region or the TNF receptor 1 (TNFR1) gene. Genet Med 5:120-125.

Sri Manjari K, Jyothy A, Shravan Kumar P, et al. (2014) A single-nucleotide polymorphism in tumor necrosis factor- $\alpha$ $(-308 \mathrm{G} / \mathrm{A})$ as a biomarker in chronic pancreatitis. Gene 539: 186-189.

Talar-Wojnarowska R, Gasiorowska A, Smolarz B, et al. (2009) Tumor necrosis factor alpha and interferon gamma genes polymorphisms and serum levels in pancreatic adenocarcinoma. Neoplasma 56:56-62.

Vassalli P (1992) The pathophysiology of tumor necrosis factors. Annu Rev Immunol 10: 411-452.

Yang Z, Qi X, Wu Q, et al. (2012) Lack of association between TNF- $\alpha$ gene promoter polymorphisms and pancreatitis: a meta-analysis. Gene 503:229-234.

Yin YW, Hu AM, Sun QQ, et al. (2012) Association between tumor necrosis factor-alpha gene -308A/G polymorphism and the risk of acute pancreatitis: a meta-analysis. J Surg Res 178: 409-414.

Address correspondence to: Xiao-bo Huang, $M D$ Department of ICU Affiliated Hospital of University of Electronic Science and Technology \& Sichuan Provincial People's Hospital Chengdu 610054

China

E-mail: xbhuang999@126.com 